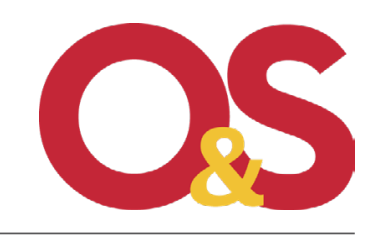

Revista Organizações \& Sociedade

\section{Psicologia moral e economia solidária: relações teóricas}

Moral psychology and solidary economy: theoretical relations

Thelma Pontes Borges

Maria Thereza Costa Coelho de Souza ${ }^{b}$

a Universidade Federal do Tocantins, Araguaína, T0, Brasil

b Universidade de São Paulo, São Paulo, SP, Brasil
2020, 27(94), 459-483

(C) Autor(es) 2020

DOI 10.1590/1984-9270944

ISSN 1984-9230

www.revistaoes.ufba.br NPGA, Escola de Administração Universidade Federal da Bahia

Recebido: 10/05/2018 Aprovado: 10/12/2018

\title{
Resumo
}

A psicologia moral é focada na compreensão de como características morais se desenvolvem e como são integradas à personalidade humana. Consideramos que o indivíduo que possua aspectos relativos aos deveres e às virtudes desenvolve uma personalidade ética. Por sua vez, a economia solidária traduz em suas práticas aspectos de comportamento ético, como preço justo, cooperação e sustentabilidade. Nosso trabalho tem o propósito de apresentar a psicologia moral como instrumental teórico capaz de favorecer os debates acerca da economia solidária, demonstrando que ambas trazem em seus princípios a formação humana, a ética nas relações e o desenvolvimento individual e comunitário. Assim, conhecer o debate sobre a psicologia moral é condição para discutir projetos de intervenção que visem à sensibilização e à formação para economia solidária.

Palavras-chave: Moralidade; Economia Solidária; Cooperação.

\section{Abstract}

Moral Psychology focuses in understanding how moral characteristics develop and how they are integrated in the human personality. We consider that an individual who presents aspects relating to the duties and virtues as central to its personality, develops what we call as an ethic personality. The solidary economy, on the other hand, translates in its practices aspects of ethical behavior, such as fair price, cooperation and sustainability. This study aims to show the Moral Psychology as a theoretical instrument able to promote debates regarding solidary economy. Despite their different final goals, both the solidary economy and the discussions on moral psychology aims, in their principles, at the human formation, the ethics in relationships and the individual and community developments. Thus, understanding the debate on Moral 
Psychology is the condition to discuss intervention projects that aim to sensitize and form the solidary economy, as it is the regulator of the actions.

Keywords: Morality; Solidary Economy; Cooperation.

\section{Introdução}

A psicologia moral se preocupa com estudos acerca do desenvolvimento de características morais a partir do nascimento, tentando compreender como tais aspectos são incorporados à personalidade humana e como passam a ser centrais ou não na identidade (La Taille, 2006; Piaget, 1932/1994). Consideramos que alguém que tenha aspectos relativos aos deveres e às virtudes como centrais, desenvolve 0 que chamamos de personalidade ética. Este trabalho tem o propósito de apresentar a psicologia moral como instrumental teórico capaz de favorecer os debates relativos à economia solidária (ecosol).

O ponto de partida desse debate é ancorado no livro 0 juízo moral na criança, de Jean Piaget (1932/1994), que tem o mérito de apresentar estudos demonstrando que a moralidade é construída de forma cooperativa entre o sujeito e o meio em que vive, podendo ou não permitir uma progressão no desenvolvimento. E é justamente a construção de uma personalidade pautada pela autonomia moral que permitirá aos atores sociais participarem de forma consciente e ativa da sociedade, alicerçada no bem comum e nas decisões coletivas.

Nesse primeiro momento, discutiremos a importância de estudar as virtudes morais (La Taille, 2000). Para tanto, recorremos à psicologia moral e à filosofia, que oferecem suporte para pensar na forma que características como generosidade e lealdade favorecem o desenvolvimento e constituem a personalidade do ser humano (Tognetta, 2009). Após, apresentaremos as principais ideias acerca de ecosol e, por fim, as relações que estabelecemos entre ela e a psicologia moral.

Acreditamos que os pressupostos da ecosol (Singer, 2002), tais como cooperação, comércio justo, autogestão, sustentabilidade, entre outros, implica o envolvimento de sujeitos que tenham tais aspectos incorporados em sua personalidade ou que estejam em processo de formação que permita tal desenvolvimento. Ao considerarmos que uma parte significativa dos empreendimentos solidários é organizada com sujeitos advindos de situações de vulnerabilidade econômica, social e educacional, a ecosol acaba sendo responsável não somente pela constituição de renda e de um ambiente educativo por ter em sua essência práticas democráticas, mas também por pensar e efetivar formações que envolvam aspectos específicos da ecosol e dos 
elementos produtivos, e também elementos facilitadores do desenvolvimento moral e da composição de uma personalidade ética.

Discutir a psicologia moral e as possíveis relações com a ecosol pode auxiliar ambas a desenvolverem pressupostos que permitam, pelo lado da ecosol, intervenções mais adequadas ao desenvolvimento humano e, consequentemente, aos avanços dos empreendimentos; e na perspectiva da psicologia moral, avanços nos estudos de intermediações que propiciem o desenvolvimento da personalidade ancorada no bem comum.

\section{Psicologia moral, notas para constituição de si}

Consideramos as virtudes importantes não somente porque participam da gênese da construção moral, mas porque constituem parte integrante da personalidade humana e por serem definidoras de ações que se refletem de forma significativa nas relações interpessoais e na sociedade (La Taille, 2000). Pais e educadores há tempos se preocupam em educar as crianças e fazê-las compreender a importância do respeito às regras sociais; obediência é o que se espera de todas. Contudo ser bom, sensível, agradável, costuma ser secundário nesses discursos; em muitos casos, nem aparece. Ser educado não quer dizer ser virtuoso com alguém. As virtudes são vistas como bônus na formação da personalidade. A obediência a deveres é exigida e muitas vezes vem atrelada à construção social de adequação ao mercado de trabalho e a uma sociedade capitalista.

Segundo Comte-Sponville (1995), a virtude "é uma força que age, ou que pode agir. Assim como a virtude de uma planta ou de um remédio, que é tratar, de uma faca, que é cortar, ou de um homem, que é querer e agir humanamente" (p. 7). É justamente a virtude de um homem que o torna tal, é ela que demarca caminhos ou desvia deles, é ela a força que Piaget (1953/1994) denomina valor. A autoavaliação que o indivíduo faz de si mesmo está definida pela valoração de si; essas representações de si organizam um quadro de quem a pessoa é e de quem é o outro. Falamos não somente de algo que é desejável, mas também que é importante enquanto constituinte do eu, que traça parâmetros no reconhecimento de si e do outro e que define forças para (poder) agir. Os estudos sobre as virtudes evidenciam sua necessidade enquanto característica humana e também nossa ineficiência em desenvolvê-la: "Pensar as virtudes é medir a distância que nos separa delas" (Comte-Sponville, 1995, p. 11).

A virtude é base e conteúdo da personalidade ética e é uma característica a ser adquirida, ou seja, não se nasce virtuoso. Para Aristóteles, é fazendo que se aprende a ser virtuoso, é sendo generoso que se aprende a ser generoso. É preciso 
criar o hábito e ir além; não basta ter uma atitude bondosa, tem que querer o bem (Comte-Sponville, 1995). La Taille (2000) ressalta que as virtudes são importantes por participarem da construção moral do sujeito e possibilitarem o amálgama da personalidade ética, pois são representativas das "qualidades das pessoas" e das análises valorativas que elas fazem de si mesmas.

O autor considera que a avaliação que cada um faz de si e do outro configura o quadro de referência de sua humanidade, e quando virtudes são acopladas ao centro da personalidade tem-se referência à ética. A participação de virtudes na personalidade é dependente também da evolução moral do sujeito (La Taille, 2006), permitindo que esse saia de uma situação de completo desrespeito às normas sociais a ponto de possibilitar-lhe a compreensão da regra como mediadora das relações (Piaget, 1932/1994). Como escreve Ramozzi-Chiarottino (2003), a teoria de Piaget "pouco a pouco, transforma-se num modelo hipotético-dedutivo do funcionamento das estruturas mentais" (p. 11).

Piaget (1932/1994) demonstra que a moral somente se desenvolve se houver condições para tanto, sendo as relações sociais responsáveis por organizar elementos adequados a tal promoção. 0 modelo piagetiano de moralidade prevê a construção progressiva desse desenvolvimento mediante condições de inter-relações que garantam tal processo. Para o autor, a moral passa pela formação de um sistema de regras na interação do sujeito com o objeto. A moralidade nesse caso não é inata, a criança nasce com ausência de regras (anomia), que se desenvolvem na relação com o meio no qual se encontra inserida. A evolução da anomia, que consiste em obedecer ao adulto, soma-se à incapacidade de a criança se deslocar de si mesma para pensar a partir de outras perspectivas e ao caráter exterior das regras sociais e seu pensamento pré-lógico, para caracterizar o que Piaget (1932/1994) denominou moral heterônoma. Essa tendência moral, que surge do respeito e amor a alguém, permite à criança uma relação ambígua com as regras, pois de um lado ela obedece e segue, mas de outro não consegue avaliar as situações, ficando presa a quem determinou a lei.

Por bem, em termos de desenvolvimento é esperado que a criança supere esse tipo de moral e desenvolva uma "moral do bem" ou autonomia moral. Conseguir coordenar pontos de vista, colocar-se no lugar do outro, utilizar a reversibilidade do pensamento, permite-Ihe trabalhar pela ótica da construção de contratos sociais e assim demonstrar sua capacidade de compreender o uso das regras sociais, não como uma imposição, mas como algo necessário para a mediação das relações em prol do bem-estar maior. Cabe lembrar que tal desenvolvimento é acompanhado pelos sucessivos processos de equilibrações, propulsores também da cognição e de sua elevação a patamares mais elevados. 
A moral da autoridade, que é a moral do dever e da obediência, conduz, no campo da justiça, à confusão do que é justo com o conteúdo da lei estabelecida e à aceitação da sanção expiatória. A moral do respeito mútuo, que é a do bem (por oposição ao dever) e da autonomia, conduz, no campo da justiça, ao desenvolvimento da igualdade, noção constitutiva da justiça distributiva, e da reciprocidade. (Piaget, 1932/1994, p. 243)

Desenvolver uma moral autônoma permite ao ser humano compreender as situações e analisá-las tendo como mote principal o bem comum. Alcançar esses aspectos do desenvolvimento tornaria o ser humano mais consciente de suas ações e de fato capaz de tomar decisões a partir de um interesse bem compreendido, considerado por Tocqueville (2000) como essencial para a democracia e para a sociedade em geral.

O filósofo Comte-Sponville (1995) nos leva a uma discussão interessante: respeitando-se as regras ou a lei nem sempre se faz justiça (lembremos que na heteronomia o respeito às normas é literal). A lei ou a regra nem sempre são justas, depende do contexto e da análise que se faz delas. A justiça em si produz o respeito à legalidade. A justiça que privilegia a equidade e/ou a igualdade se torna um valor. A justiça como valor transforma-se em virtude, pois sua essência é virtuosa. Assim, percebemos que a justiça pode ser compreendida como legalidade (heteronomia) ou como valor (autonomia). No primeiro caso, o simples cumprimento da lei pode gerar injustiças, visto que acaba por realizar um dever cego, descontextualizado e imposto, típico da heteronomia, que segue e obedece a um líder/regra/lei soberana, sem conseguir analisar o todo. No segundo, justiça como valor, o bem comum apresenta-se acima da regra/lei, e é esse bem comum que determina o que é ou não justo, independente da legalidade. $O$ autor define num primeiro momento a justiça na heteronomia e num segundo na autonomia moral. A justiça na autonomia moral tem o caráter de virtude, pois configura-se como valor, tal como a generosidade, polidez etc.

Podemos considerar que Piaget (1932/1994) se debruça sobre uma virtude para pensar a estrutura da moralidade humana. Como tratou do sujeito epistêmico, "um sujeito ideal, universal, que não corresponde a ninguém em particular, embora sintetize as possibilidades de cada uma das pessoas e de todas as pessoas ao mesmo tempo" (Ramozzi-Chiarottino, 1988, p. 4), nos possibilita ver e analisar aquilo que tem de geral no desenvolvimento humano e pressupor alguns fatores, como: qual o sujeito epistêmico ideal para a economia solidária? No caso em questão, é aquele que desenvolve uma estrutura moral autônoma e tem no centro de sua personalidade virtudes que permitem uma valoração de si e do outro focada no bem comum. Ao definir o ideal teremos que pensar, a partir dos atores sociais reais da ecosol, em que ponto se encontram em termos de desenvolvimento moral e promover, pela intensificação 
das relações cooperativas e democráticas e pelos cursos de formação, aspectos constitutivos da personalidade.

Os estudos sobre as virtudes abrem caminhos para irmos além da psicologia moral e debatermos uma psicologia da personalidade e do desenvolvimento, uma vez que o desenvolvimento do caráter passa necessariamente pelo desenvolvimento da ética e da moral (La Taille, 2000, 2006; Taylor, 2011a, 2011b; Tognetta, 2009). Veremos que, para além das escolas e famílias, instituições reconhecidas pelas intervenções educativas, a ecosol se configura enquanto ambiente propício e facilitador do desenvolvimento humano. As virtudes e sua incorporação à personalidade tornam-se importantes, pois "as virtudes remetem-nos a dimensões universais, pois essencialmente humanas, a saber: qualidade atribuída à pessoa, valor desejável e admirável, leitura ética da personalidade. Pensamos que isto já basta para avalizar um estudo psicológico das virtudes" (La Taille, 2000, p. 113).

As características que descrevem a universalidade das virtudes demonstram aspectos interessantes quanto à incorporação dessas ao eu, definindo valores sobre si mesmo e determinando quais são desejados e apreciados. Se as virtudes definem quem é a pessoa, a personalidade deve ser compreendida por meio do olhar da ética. E se as primeiras são reconhecidas e produzem as leituras de caráter de si e dos outros, a segunda deve ser estudada tanto como parte da psicologia do desenvolvimento como da psicologia da personalidade. Assim, precisamos ampliar a compreensão que há sobre o desenvolvimento de virtudes e passar a tratá-las como essenciais para a compreensão do ser humano e da sociedade.

A despeito da clareza que hoje se estabelece quanto à importância das virtudes, percebemos que nem sempre foi assim, visto que apesar de termos importantes trabalhos na psicologia moral, a maioria se interessou muito mais por aquilo que seguia uma tradição kantiana ${ }^{1}$, ou seja, a preocupação centrava-se na questão da justiça. Piaget (1932/1994) foi um deles. Precursor nos estudos psicológicos sobre o desenvolvimento moral, fundamentou parte de suas ideias dentro de uma perspectiva kantiana, utilizando para isso o portfólio sobre justiça e imperativos. Trabalhou a moral como um conjunto de regras resultando em deveres morais. Kohlberg, Boyd e Levine (1990/2002), seguidores de Piaget, também elaboraram seus trabalhos em torno da moral enquanto justiça, desenvolvendo um arcabouço teórico com base em vastas pesquisas empíricas que demonstram o caráter desenvolvimentista e progressivo da moralidade na personalidade.

1 Kant fundamenta sua noção de moral no campo da racionalidade pelo que chamou de imperativos categóricos, ou seja, a compreensão de que qualquer comportamento deve basear-se no fato de que seu ato pode ser considerado uma lei universal (La Taille, 2006). 
Devemos considerar que os estudos da psicologia moral não trabalham com a viabilidade do desenvolvimento unicamente a partir do ponto de vista do sujeito como se bastasse estar vivo para progredir -, tampouco somente com as contingências do meio social - como se treinamentos e condicionamentos resolvessem o problema. Estamos falando de um cenário em que para se estabelecer é preciso que fatores individuais, sociais e coletivos interajam, uma vez que aspectos morais são resultados de relações interindividuais (Pedro-Silva \& Ferreira-Costa, 2017).

Nesse caso, ressaltamos que os aspectos envolvidos nas práticas cotidianas da ecosol, como solidariedade e democracia, configuram-se como elementos favoráveis ao desenvolvimento das estruturas morais por se constituírem em relações sociais cooperativas, o que para Piaget (1932/1994) é fator necessário às formações cognitivas e morais por possibilitarem a descentração com base nos diálogos e acordos.

La Taille $(2000,2006)$ nos mostra o quanto é complexo o tema e propõe que se faça um aprofundamento nas discussões acerca do conceito de moral e de ética, considerando que não é possível estudar as virtudes sem antes ter clareza desses pontos. Demonstra que a ética é demarcada pelos princípios que guiarão os deveres, ou seja, "quem eu sou" e "o que quero" determinam o que farei em termos morais. A justiça impõe direitos e deveres para se fazer justa, contudo a generosidade ou outra virtude não passam pelo dever; caso o fosse, não seria virtude. A virtude é marcada justamente pela não obrigatoriedade. Ninguém é obrigado a ser generoso, porém se o for, será admirado e considerado moralmente bom. Dessa forma, a moral deixa de ser somente a moral da justiça, marcada por deveres e direitos, e se amplia para uma moral do bem, das virtudes; em consequência o plano teórico se altera e a referência kantiana cede lugar à aristotélica com as discussões acerca da felicidade.

Aristóteles (2009) escreve que a finalidade humana é a felicidade, esta não se fundamenta somente no prazer, mas na capacidade de o homem se identificar com o viver bem e o fazer o bem. Ela não é uma disposição, é uma atividade que exige dedicação, que só se fundamenta na virtude. Uma vida virtuosa possibilita a felicidade. A felicidade é ação virtuosa, e não divertimento, apesar de o divertimento com moderação disponibilizar as pessoas para coisas sérias. Uma vida feliz é aquela pautada pelas virtudes. A vida boa é, para La Taille (2006), uma definição de ética, viver uma vida que vale a pena ser vivida, com projetos que incluam a si mesmo e aos outros. Ou seja, prospecções que incluam o bem comum como parte de si e do outro são definidoras da ética. Ao saber quem somos (ética), definimos como agimos (moral). Nesse sentido, a ética define os princípios do comportamento moral.

Gilligan (1982) nos auxilia nesse processo de ampliação do assunto e, apesar de diferenciar a moral a partir do gênero, os homens mais propensos à ética da justiça e as mulheres à ética do cuidado, consegue estabelecer um debate interessante 
acerca de uma moral do cuidado, pró-social, que preserva os relacionamentos e se responsabiliza por eles. "Assim, as mulheres não apenas se definem num contexto de relacionamento humano, mas também se julgam em termos da sua capacidade de cuidar" (p. 27).

Essa dicotomia entre a ética da justiça e a ética do cuidado como sendo típica do gênero é ampliada pela autora, que considera que existem homens que desenvolvem a ética do cuidado, bem como mulheres que desenvolvem a ética da justiça. Independentemente do debate de gênero, essa autora auxilia na abertura do campo para argumentações de novas formas éticas de se relacionar que não passam necessariamente pela obediência à regra social imposta ou pelo conceito de justiça.

Os estudos das virtudes ou da chamada moral pró-social, inaugurados por Gilligan (1982), permeiam características do ser humano que constituem o eu, a personalidade ou o self. Por isso, entramos num terreno mais subjetivo, mais afetivo. A maneira valorativa como uma pessoa se vê e se reconhece pode necessariamente passar pelo reconhecimento das virtudes. Mesmo ausentes, as virtudes se configuram como importantes por demonstrarem aquilo que falta a si e ao outro. "A generosidade parece dever mais ao coração ou ao temperamento, a justiça, ao espírito ou à razão" (Comte-Sponville, 1995, p. 97). Assim, um estudo psicológico da moral pró-social auxilia na compreensão do desenvolvimento humano, da constituição da personalidade e ainda permite discutir ações pessoais na sociedade, no trabalho, enfim, na vida. As pesquisas no campo da psicologia moral caminham para a percepção de que a constituição de si mesmo passa (ou não) por elaborações tanto no plano ético quanto no moral. Sendo a ética o guia das ações, o comportamento será moral quando a personalidade se constitui por meio da expansão de si mesmo com a incorporação de valores morais e virtudes; caso contrário, o sentimento e a ação moral serão fracos (La Taille, 2010).

As representações que o sujeito desenvolve sobre si devem envolver valores positivos de si mesmo, compreendendo-se valor como uma ligação afetiva intensa ou um investimento energético alto (Piaget, 1953/1994) que aloca elementos à frente de outros em ordem de importância. Dessa maneira, alocar virtudes na personalidade e se ver como tal permite ao sujeito constituir uma escala de valores firme o bastante para superar conflitos (Freitas, 2003; La Taille, 2006, 2010).

A busca de uma vida boa implica a busca de uma vida com sentido, e uma vida que faça sentido deve, necessariamente, contemplar a expansão de si próprio que se traduz pela busca e manutenção de representações de si com valor positivo. (La Taille, 2010, p. 113) 
O autor destaca que a busca de sentido e a expansão de si são elementos, ainda que não os únicos, necessários à constituição da ética humana.

A constituição de si como sujeito ético é resultado das imbricadas relações que ele estabelece com o social. Ambientes em que há predomínio de relações cooperativas, em que a verdade prevalece e existem instituições justas, são passíveis de desenvolver pessoas com virtudes alocadas no centro de sua personalidade, possibilitando 0 surgimento do respeito de si e de uma vida que faça sentido para si e aos demais. Isso é para La Taille $(2006,2009)$ a personalidade ética. E complementando, Puig (1998) propõe que a dimensão moral deve ser incorporada à personalidade humana, nas proposições e reflexões que acontecem no cotidiano, possibilitando consciência e delimitando um eixo condutor do fazer moral, tal como a estrutura autônoma para Piaget.

Puig (1998) diz: "A construção da personalidade moral é uma obra compartilhada, feita junto com os outros, e impulsionada por normas de valor que a orientam, ainda que nunca a determinem completamente" (p. 20). Considerando o autor, valemo-nos da ideia de que o ambiente da economia solidária é (ou pode ser) coautor participativo das possibilidades de produção de sujeitos éticos, sobretudo pelas relações horizontais que possibilitam trocas e responsabilidades reais e pelos valores institucionais justos que orientam o fazer no grupo e na sociedade.

\section{Economia solidária, notas para o bem-viver}

Trabalhados aspectos importantes sobre a psicologia moral, devemos nos centrar nas principais ideias de economia solidária, o segundo ponto de discussão deste texto. Mostraremos que a conceituação e o debate em torno da ecosol traçam aspectos para seu funcionamento que necessariamente precisam que seus envolvidos tenham ou estejam dispostos a se descentrar e a desenvolver e praticar ações que considerem o outro tanto quanto a si mesmo. Em outras palavras, a ocorrência de ecosol, com todas as suas prerrogativas, é dependente dos processos subjetivos de seus participantes, fazendo com que o trabalho educativo formativo tenha valor especial e interveniente no processo (La Taille, 2006; Taylor, 2011a, 2011b).

O termo economia solidária é múltiplo e ainda carece de um delineador comum, podendo produzir ambiguidades e contradições em sua compreensão e gerar críticas diversas. Podemos considerar então que se trata de um termo em construção e com matizes variadas (Pinheiro, 2013). A definição retirada da Secretaria Nacional de Economia Solidária (Senaes, 2004) e resultado dos trabalhos de Paul Singer, apesar de consagrada é também uma das mais criticadas por considerar que a ecosol, enquanto modelo socialista, pode funcionar dentro de um sistema de mercado pela simples concorrência e sem grandes alterações estruturais do sistema. 
A ecosol é definida por um conjunto de atividades econômicas que se diferenciam pelas formas de produção, de sustentabilidade, de preço justo, distribuição, entre outros, envolvendo fatores como propriedade coletiva dos bens e/ou da mão de obra, participação democrática nos rumos da organização e distribuição igualitária de renda, além de trazer como forma de gestão a autogestão, em que ocorrem processos coletivos e democráticos de decisão, uma vez que todos os participantes têm voz e voto em assembleias (Singer, 2002). Para Singer, essas características têm o mérito de serem educativas e de transformarem as ideologias das pessoas, de forma a pensarem e a atuarem fora do modelo capitalista da sociedade. Essa visão traz a ideia de que, pelas brechas do capitalismo e com o apoio do Estado, é possível se organizar de outra forma e fazer frente pela concorrência e eficiência dos empreendimentos (Pinheiro, 2013).

Pinheiro (2013) expõe que coadunam com o pensamento de Singer autores como Mance (1999), Novaes e Dagnino, que ampliam a visão a partir da constituição de redes solidárias em nível local, regional e mundial. Os autores acreditam que o sistema capitalista pode ser destruído pelo crescimento da economia alternativa e pela constituição de um mundo solidário. Nesse sentido o Estado seria forte, mas a partir da governança democrática da sociedade. Nesse olhar, a ecosol cresce até substituir o modelo capitalista. Numa outra vertente, França Filho tem ideias semeIhantes às de Laville, apresentando a ecosol como uma economia híbrida e plural, que se submete às prerrogativas da ação coletiva e convive com outras economias (Pinheiro, 2013). Benini e Benini (2010) colocam a autogestão na ecosol como forma de enfrentamento e resistência perante o capitalismo, apontando para a construção de uma consciência coletiva e inaugurando novas subjetividades. Esses autores ainda digerem que a ecosol se institui em uma dupla frente, a primeira como uma forma alternativa de trabalho e renda e a segunda por instalar novas sociabilidades humanas a partir da solidariedade (Benini \& Benini, 2015).

Outra forma de compreender a ecosol é como movimento social, por fazer frente às desregulações do mercado e às desigualdades sociais e reivindicar, além de renda, aspectos relativos aos direitos sociais. Essa visão é de enfrentamento do capitalismo e defende políticas públicas e financiamento para sua efetivação. São partícipes desse olhar autores como Tauile (2002) Tiriba (2008) e Albuquerque (2003), aos quais acrescentamos, entre outros, Boronat (2010) e Picolotto (2008), que compreendem que a ecosol, enquanto movimento social, altera condições culturais, como o consumo e a relação produtor-consumidor, tornando-a ética e engajada. Pinheiro (2013) circunscreve-se a Gaiger e Carrion, que consideram o poder emancipatório da ecosol e a geração de trabalho e renda, mas não acreditam que seja possível uma transformação radical da sociedade, com alterações significativas nas estruturas. Seja qual for a visão sobre ecosol, as críticas referem-se às diversas 
impossibilidades de superação/convivência do capitalismo e ou como utopias experimentais, que geram ainda mais exploração e diminuem os direitos trabalhistas.

Oliveira (2017) apresenta os autores críticos à ecosol e os enquadra: Vainer a considera uma utopia experimental; Wellen, Bonfim, Menezes, entre outros, entendem que a ecosol apenas precariza o trabalho e não consegue fazer frente ao capitalismo; Quijano não acredita no poder emancipatório da prática. Oliveira (2017) ainda inclui nas visões de ecosol os debates sobre gênero a partir dos estudos de Carolina e Toledo, por considerá-lo essencial na nova reestruturação social. "Diante do exposto, pode-se observar uma diversidade de opiniões sobre as definições da Economia Solidária. Esta foi conceituada como programa, projeto, filosofia de vida, fenômeno, conceito, teoria, realidade, política pública, tecnologia social, movimento social e utopia experimental". (Pinheiro, 2013, p. 92).

Independente da visão escolhida, há uma concordância nas características das organizações da ecosol, com foco na autogestão, sustentabilidade e democracia. Singer (2002) escreve que o potencial educativo permitiria o aparecimento da solidariedade, igualdade e coletividade como valores ideológicos. Não seriam esses valores ideológicos citados por Singer os mesmos sugeridos pela psicologia moral nos estudos sobre as virtudes? São essas prerrogativas gerais que nos interessam, isentas da discussão e do enquadramento que as suscitam nas estruturas sociais e econômicas.

Enfim, podemos dizer que, de forma implícita, Singer sugere uma relação de codeterminação entras as práticas de trabalho autogerido e os valores ideológicos de Economia Solidária, que pode ser mais ou menos expressa da seguinte maneira: à medida que o sujeito se envolve nas práticas econômicas de autogestão, ele é educado para a autogestão e à medida que ele é educado, mais ele pratica e incorpora os valores da autogestão, que por conseguintes são os valores ideológicos da Economia Solidária. (Azambuja, 2009, p. 284, grifo do autor)

A economia solidária aparece em grupos informais, em clubes de trocas, redes de vendas, associações ou cooperativas que fundamentam suas práticas na participação equitativa e democrática, na cooperação de ideias e ideais e na construção coletiva do ambiente de trabalho. As decisões são tomadas em prol da maioria, prevalecendo o bem comum como condutor das decisões. Em publicação do Instituto de Pesquisa Econômica Aplicada (Ipea, 2018), num trabalho bibliométrico sobre ecosol, demonstra-se que as pesquisas no Brasil são multiáreas, multidisciplinares e descentralizadas, não se concentrando em determinados pesquisadores e/ou centros de pesquisa, além de coadunar com Pinheiro (2013) ao demonstrar que existem vieses e olhares que ora se distanciam, ora se complementam, ora se opõem. 0 que não 
se pode negar é a força do debate e da prática da ecosol nos últimos anos, conforme indica Santos (2014) ao estudar a configuração de formação do Fórum Brasileiro de Economia Solidária e perceber que a prática democratizante dos empreendimentos é transposta para outras esferas da vida dos sujeitos participantes.

As propostas da ecosol proporcionam discussões acerca de modificações profundas na sociedade, que englobam tanto a forma de produzir e vender quanto a de consumir, instalando a lógica de um "consumo solidário", que segundo Mance (1999) "ocorre quando a seleção do que consumimos é feita não apenas considerando o nosso bem-viver pessoal, mas também o bem-viver coletivo, uma vez que é no consumo que a produção se completa" (p. 13). Essa atividade econômica segue princípios éticos que podem ser descritos como relativos à boa vida e ao bem-viver (La Taille, 2006; La Taille \& Cortella, 2005), garantindo trabalho e renda a setores excluídos socialmente, participando da construção de uma sociedade mais solidária com os valores fundamentais. Para Singer (2002), a autogestão concentra parte importante das práticas que envolvem a economia solidária. Vejamos a definição de autogestão proposta no Dicionário internacional da uma outra economia": "A autogestão é um projeto de organização democrática que privilegia a democracia direta. Esta constitui um sistema em que voluntariamente, sem perceberem remuneração e sem recorrerem a intermediários, os cidadãos debatem todas as questões importantes, em assembleias" (Mothé, 2009, p. 26).

A autogestão permite a participação direta dos membros nos empreendimentos solidários, decidindo todos os aspectos, sejam eles econômicos ou sociais. Singer (2002) aponta que a maior dificuldade da ecosol é justamente a prática autogestionária, uma vez que ainda não aprendemos nas escolas a participar ativamente e de forma democrática. Podemos afirmar que as propostas da ecosol, incluindo a prática autogestionária, passam necessariamente por um projeto educativo que valorize relações de cooperação e participação. A economia solidária surge, sobretudo, pela necessidade de grupos sociais em situações de extrema vulnerabilidade se utilizarem das relações solidárias na configuração de cooperativas e/ou associações, como forma de superação da aleatoriedade de participação na vida social e econômica e na tentativa de suplantação da incerteza de sobrevivência. A possibilidade de a economia solidária favorecer a diminuição das desigualdades sociais foi captada principalmente por grupos políticos vinculados a partidos de esquerda e implementada como políticas públicas na última década.

Cada vez mais vemos crescer grupos interessados em estudar, trabalhar ou participar de empreendimentos econômicos solidários, conforme verificamos no mapeamento feito pelo Sistema Nacional de Informações da Economia Solidária (Sies, 2013). A percepção disso decorre do aumento do número de Incubadoras Tecnológicas de Cooperativas Populares (ITCP) com a criação, no primeiro mandato 
do governo Lula, da Senaes, com secretarias municipais de fomento da economia solidária em diversas cidades do país e com o aparecimento cada vez maior da temática em revistas das mais diversas ordens, como por exemplo, Cadernos de Gestão Social da Universidade Federal da Bahia (UFBA), Revista de Economia Solidária da Associação Centro de Estudos em Economia Solidária do Atlântico. Apesar de vermos um movimento, na atualidade, de desmonte das políticas e organizações em prol da ecosol, ela ainda se faz forte e resiste às investidas neoliberais do novo governo.

Sabemos, contudo, que só ocorre ecosol e organização político-social em grupos, associações e/ou cooperativas se o interesse surgir das próprias relações sociais e se os princípios que permeiam a ecosol forem internalizados e seguidos por todos os participantes; além do mais, políticas públicas impostas pouco favorecem as organizações se essas não nascerem de processos solidários. O aumento do interesse na área por parte dos sujeitos participantes dos empreendimentos solidários se deve, num primeiro momento, à busca por uma fonte de renda alternativa, principalmente em momentos de crises econômicas e o consequente aumento do número de desempregados, uma vez que a ecosol está mais presente em grupos socioeconomicamente vulneráveis. Num segundo momento, por conta das possibilidades de participação nos cursos formativos ofertados pelas incubadoras e pelos empreendimentos de ecosol, os atores envolvidos descobrem a possibilidade de emancipação social e de luta por igualdade de direitos e equidade de políticas (Borges, 2014).

Apesar de os empreendimentos de ecosol terem como base a solidariedade, as vivências em situações sociais se definem pela complexidade na busca por conciliação de necessidades individuais com coletivas, diferenças pessoais, gostos, pensamentos e pontos de vista, dificultando o processo e resultando em movimentos de avanços e retrocessos sucessivos. 0 ambiente social pautado pelo debate e por acordos coletivos é o mesmo gerador de discordâncias, conflitos e desconfianças nas relações. Para que esse espaço se valha e se constitua em um ponto convergente de progressos, é necessário que todos trabalhem em prol do bem comum; caso contrário, perdurarão a politicagem, os arranjos e as negociatas, desvirtuando por completo os objetivos da ecosol ou acabando por criar um processo democrático fragilizado na essência. Demo (2005) escreve:

O termo sociedade igualitária condensa esta complexidade dialética de pessoas ao mesmo tempo iguais e diferentes, que são capazes de se doarem para a comunidade sem perder sua individualidade, ou que são capazes de construir oportunidades de desenvolvimento próprio sem destruir a dos outros. (p. 60) 
A ecosol surge no seio das comunidades e tem como pilar a plena participação e a emancipação de seus participantes (Benini \& Benini, 2010, 2015). Tal emancipação que respeita os mais diversos saberes pode ser pensada e entendida como sendo do ponto de vista social, político, emocional ou econômico. A autogestão, um dos princípios dessa "outra economia", apresenta-se como uma alternativa à administração e às formas de gestão positivistas, que impedem a emancipação de seus atores (Cançado, Tenório, \& Pereira, 2011). A economia solidária tem como pressuposto a promoção da cidadania e a democracia como fonte de decisões, considerando sempre a responsabilidade social (Singer, 2002). Percebemos que o bem comum e individual é o ponto de intersecção entre a psicologia moral e a ecosol, sendo que as duas se constituem em um norte para os comportamentos sociais. Os estudos de psicologia moral consideram o bem comum como resultado de uma característica produzida ou a ser desenvolvida no ser humano, viabilizada pela incorporação de virtudes morais na própria personalidade (Comte-Sponville, 1995; La Taille, 2006; Puig, 1998; Taylor, 2011b). O desenvolvimento do bem comum como característica da personalidade ética é, dessa forma, condição importante para a ecosol, pois demarca a forma de ser e de agir das pessoas. 0 bem comum pode garantir relações sociais mais éticas e recíprocas e favorecer trocas econômicas fundadas nesse pressuposto. Somente o bem comum pode gerar coletividade, equidade e decisões que preservem a maioria. "A ética da convivência igualitária guarda como referência maior o bem comum. Este não pode ser incompatível com preferências pessoais, mas estas não podem preponderar" (Demo, 2005, p. 59).

Singer (2002) foi muito feliz em colocar como a prática educativa participa dos processos na ecosol e em dizer o quanto tal prática é definidora de um empreendimento solidário. "O perigo da degeneração da prática autogestionária vem, em grande parte, da insuficiente formação democrática dos sócios" (p. 21). 0 autor nos alerta que sem os processos educativos a autogestão pode falhar, uma vez que dependem diretamente de uma disposição/intervenção democrática ou, nas palavras de Piaget (1953/1994), de uma descentração cognitiva e da capacidade de se colocar no lugar do outro, atuando por cooperações mentais.

\section{Relações entre psicologia moral e economia solidária}

Pensemos que tanto a ecosol e a autogestão como as discussões acerca da psicologia moral demonstram que, em seus princípios, apesar de objetivos finais diferentes, visam ao desenvolvimento individual, social e comunitário e à formação humana geral. A ecosol possibilita inserção política, social e econômica de seus participantes, pois garante a politicidade, a autonomia e a possibilidade de conquistar os próprios caminhos (Demo, 2006). A solidariedade é, para Laville (2016), uma forma de diminuir 
os efeitos nocivos de uma economia de mercado e de criar laços sociais diferenciados, baseados na ação coletiva e numa nova forma de cidadania, livre e participativa. 0 autor considera ainda que essa nova forma de organização extrapola o campo econômico demonstrando metamorfoses de relações que se estabelecem entre o espaço associativo e público, reverberando na sociedade novas maneiras de socialidade.

Diante das investidas neoliberais cada vez mais intensas em nosso país e das novas políticas de terceirização e de reforma trabalhista, a ecosol se reatualiza como forma de negociação/enfrentamento de um sistema que, cada vez mais, diminui o Estado de bem-estar social e aumenta as diferenças entre os grupos (Castel, 2015). Os princípios pautados pela ecosol, mesmo que ainda pouco incorporados, demonstram um projeto de vida e de país comprometido com a cidadania. Conforme Laville (2016), para ocorrer a economia solidária é necessário unir a dimensão econômica à política, considerando que, apesar de se configurar como empreendimento privado, oferece um repertório de ações coletivas típicas dos espaços públicos e das ágoras.

Recorrem, portanto, a meios econômicos para atingir finalidades que tangem ao modelo de sociedade: justiça social, preservação ambiental, diversidade cultural, entre outros. Em outras palavras, sua ancoragem no espaço público modifica seu modelo econômico, pois elas procedem a uma hibridização de recursos (comerciais, redistributivos, reciprocitários), visando à realização de um projeto coletivo. (p. 375)

A autogestão, característica da ecosol, só pode ser pensada se o indivíduo participante do processo tiver desenvolvido a autonomia moral ou se estiver em processo de múltiplos conflitos cognitivos propiciados pelo ambiente recíproco e cooperativo gerador de desenvolvimento. A autogestão é um estilo de gerência que elimina o proprietário/chefe, estabelecendo relações horizontais com predomínio da solidariedade e da democracia. Para que funcione de forma adequada, é necessário que seus membros tenham interesse bem compreendido, pois agirão conforme sua consciência na hora de votar e tomar decisões.

O interesse bem compreendido depende sobremaneira da capacidade individual subjetiva de cada sujeito, uma vez que se ele não tiver desenvolvido a autonomia moral, seus comportamentos serão pautados pela lei instituída por aquele que assumir o lugar de referência. Nesse caso, a cegueira moral, típica da heteronomia, instituída pelo não desenvolvimento da personalidade com a influência de outros, pode gerar situações e decisões vinculadas aos favorecimentos pessoais ou de grupos específicos. Por outro lado, se há no ambiente prevalência de cooperação, solidariedade e formação, existe também a possibilidade de ele funcionar como um acelerador das reestruturações cognitivas e morais, promovendo alterações nos esquemas de pensamento do sujeito, 
favorecendo a incorporação dos princípios da economia solidária à personalidade. Ou seja, pode haver uma retroalimentação: o espaço colaborativo, formativo e dialógico facilita o desenvolvimento moral, bem como a personalidade ética permite a incorporação e a ação pautadas pelos princípios da economia solidária. Borges (2014) mostrou em sua pesquisa que provavelmente as formações promovidas por uma associação facilitaram alterações na constituição ética dos sujeitos envolvidos.

A autonomia é considerada por Piaget (1932/1994) o ápice do desenvolvimento moral, momento em que a capacidade de avaliar a situação e priorizar o bem aparece acima de tudo. Freitas (2003) escreve que, para Piaget, "o bem, portanto, não é nem individual nem interindividual; o bem é o equilíbrio ideal, lei tanto para as personalidades quanto para a própria sociedade" (p. 53). Cabem a nós análises e avaliações que permitam verificar quais as características dos grupos de ecosol a fim de buscarmos pelo ideal de sujeito epistêmico sugerido por Piaget. $\mathrm{O}$ alcance à autonomia moral depende sobremaneira dos espaços coletivos e dos tipos de relações sociais estabelecidas. Para Piaget (1932/1994), um ambiente com prevalência de relações coercitivas somente reforça a permanência na heteronomia moral. Em outros termos, o universo do mundo do trabalho, das escolas, das igrejas, enfim, das instituições, é em geral reforçador da imaturidade psicológica e da possibilidade de manutenção da cegueira moral, bem como da liderança por pessoas e grupos específicos da sociedade. Contudo, relações simétricas e dependentes de acordos mútuos criam as condições necessárias para a progressão psicológica e a superação da moral infantil. Dessa forma, a cooperação se institui como um tipo desejado de relação social, haja vista possibilitar a apuração da personalidade ética, alocando o bem coletivo à frente das questões individuais.

Entender como "o bem" é incorporado à personalidade é condição para discutir projetos de intervenção que visem à sensibilização e à formação para a ecosol, pois ele é o regulador das ações. A personalidade ética a viabilidade econômica e os aspectos da comunidade envolvida têm igual importância, sendo as relações democráticas e igualitárias o norte de funcionamento. A psicologia nos auxilia a pensar a autonomia do ponto de vista moral, a aquisição de virtudes e a constituição de um self ético. Isso é importante por acreditarmos que a compreensão de semblantes relativos à personalidade dos atores da ecosol pode favorecer o trabalho de educação e de incubação desses empreendimentos. Os aspectos dos princípios da ecosol pedem que seus participantes tenham desenvolvido características morais, afetivas e cognitivas tais como reciprocidade, cooperação, respeito mútuo, descentração e "pequenas" virtudes, como a generosidade e a humildade, ou seja, que tenham desenvolvido uma personalidade ética. Talvez a própria participação nesses empreendimentos possibilite tal desenvolvimento, uma vez que pesquisas demonstram que ambientes cooperativos favorecem a expansão moral e a incorporação de virtudes específicas (Tognetta, 2003, 2009; Vinha, 2009). 
Vinha (2009) escreve que para desenvolver a moralidade são necessárias experiências de vida social, pois nelas se discutem os problemas e se compreendem as regras como algo estabelecido para o bem comum e para a melhor convivência de todos. 0 que esses espaços coletivos gerados pela autogestão fazem a não ser propiciar justamente essas vivências? As assembleias, os debates coletivos e as ações em decorrência das falas e decisões estabelecidas são relações que não se fundam em autoridades externas ou internas, e sim na dialogicidade e nos contatos horizontais do grupo. Mesmo os momentos de conflito e desgaste podem ser compreendidos como inerentes aos espaços decisórios, mas se mantida a construção narrativa do grupo e respeitados os posicionamentos nas votações, fundam-se ambientes propícios ao desenvolvimento da moralidade e de sua incorporação à personalidade.

Piaget (1932/1994) e La Taille (2006) trabalham a noção de que quando um sujeito elabora seu projeto de vida e age socialmente de acordo com os princípios que escolheu, é sinal de que possui uma personalidade ética. A ética somente é possível em personalidades autônomas, garantindo o mais refinado grau de socialização. Freitas (2003), tratando das questões relativas à formação da personalidade autônoma e da possibilidade de conservação de valores, escreve: "O sujeito pode . . . estabelecer fins prioritários a longo prazo e conduzir-se em função deles. Posteriormente, as novas possibilidades abertas pelo pensamento formal permitem que esses fins prioritários ultrapassem as fronteiras do real, dando origem aos ideais" (p. 114).

Assim sendo, tanto para participarmos democraticamente como para nos filiarmos a propostas ideológicas, com ideais sociais coletivos, é necessário termos em curso a formação de uma personalidade autônoma e ética. Reiteramos que nos estudos de psicologia moral e na epistemologia genética de Piaget, apesar de grande parte das pesquisas ser realizada com crianças, a teoria constituída permite falar em desenvolvimento humano independentemente da idade ou do momento da vida. Ou seja, Piaget estudou os caminhos esperados para o desenvolvimento moral a partir da infância, elaborando informações quanto à progressão das tendências morais. Contudo, não há garantias de que essas ocorrerão no tempo esperado. Dessa forma, apoiamo-nos em um pressuposto do próprio autor quando considera que é possível desenvolvê-la ao longo de toda a vida, desde que sejam criadas as condições necessárias para as sucessivas reelaborações cognitivas, frutos de um ambiente cooperativo e desafiador ao pensamento.

Percebemos que a ecosol e a autogestão oferecem informações e formações interessantes em termos de participação social que vislumbram o respeito ao próximo e suas contribuições no debate em espaços públicos, a descentração cognitiva e emocional e o exercício da cidadania que, a nosso ver, são justamente facilitadores das novas equilibrações do pensamento. Não queremos com isso dizer que os processos de gestão democráticos e participativos acontecem de forma tranquila, 
mas precisamente mostrar que é na possibilidade de encontro/confronto com os ideais do outro que se podem constituir novas maneiras de ver e pensar a sociedade. Esses espaços, marcados pelos princípios da ecosol e da autogestão, nos permitem vislumbrar, mesmo que de forma ideológica, aspectos científicos que estejam à mercê do bem-estar social e do homem enquanto ser individual participante de uma coletividade. Nos permite ver outros espaços educativos que podem e devem assumir como estratégia intervenções que considerem aspectos do desenvolvimento humano, especificamente a constituição de uma personalidade que tenha em seu centro valores morais e autonomia de pensamento.

Em revisão bibliográfica, verificamos que existem inúmeros trabalhos na área de cooperativismo, gestão social, autogestão e economia solidária, contudo encontramos poucos que consideram o sujeito em si, que façam uma análise do desenvolvimento daquele que participa desses empreendimentos. Como diz La Taille (1994), estuda-se a guerra, mas poucos estudam os guerreiros. Afirmamos a necessidade de estudarmos os guerreiros da ecosol a fim de verificar se esses possuem características morais facilitadoras de suas práticas e discutir que aspectos são favorecedores do desenvolvimento moral e da construção de uma personalidade ética. Pela literatura especializada, participantes de ambientes cooperativos exercem a descentração, o respeito mútuo e outros aspectos relativos ao desenvolvimento moral. A construção coletiva de regras e o desenvolvimento do bem-estar em decorrência dos acordos feitos, inclusive das punições a serem adotadas, garantem a participação coletiva, a diminuição do egocentrismo e da unilateralidade nas relações sociais (La Taille, 2006; Tognetta, 2003; Vinha, 2009). O intercâmbio permanente com outras formas de pensamento processa os desequilíbrios necessários, defendidos por Piaget (1932/1994) como essenciais para o desenvolvimento moral, cognitivo e emocional.

A educação autoritária tende a formar seres humanos submissos, conformistas e seguidores de uma autoridade, o que caracteriza a moralidade heterônoma (Piaget, 1932/1994). Relações de coerção foram trabalhadas por Piaget ao longo dos seus estudos sobre moralidade, demonstrando o quanto esse tipo de relação social, se predominante no ambiente, não favorece novas estruturações sociais e morais, condenando os participantes a uma moralidade heterônoma, típica daqueles que tão somente obedecem às regras, sem questionar os efeitos ou os porquês das determinações infringidas. Esses ambientes coercitivos são predominantes em nossa sociedade, razão por que a maioria das escolas reforça o lugar da autoridade e vincula a aprendizagem à obediência. Esse modelo se repete nos espaços de trabalho em que persiste a heterogestão e mais uma vez define-se o lugar de quem manda e de quem obedece; premiam-se os que se adequam ao contexto com bom comportamento: na escola, "estrelinhas"; no trabalho, "bônus e/ou fotos de funcionário do mês", sempre reforçando o lugar de submissão e de não participação social. 
Essas esferas de reforçamento do status quo produzem o recrudescimento da heteronomia moral na população em geral, que fica sem espaços de compartilhamento de ideias e ideais e sem saber/aprender a transformar angústias pessoais em dilemas da coletividade. Nessa lógica, a individualidade vence a coletividade, facilitando a manipulação das massas. Por outro lado, seguindo Piaget, Tognetta (2003) nos mostra que crianças advindas de ambientes cooperativos, mesmo sendo mais novas, desenvolvem senso de solidariedade em comparação com crianças mais velhas frequentadoras de ambientes coercitivos, distinguindo que os tipos de relações sociais interferem diretamente no desenvolvimento da reciprocidade humana.

Piaget (1932/1994), por sua vez, deixa claro que o que gera desenvolvimento não é o respeito por uma regra exterior, e sim a participação mútua na construção das regras coletivas. Percebemos que o ambiente proposto nos empreendimentos solidários mira as características favorecedoras do desenvolvimento humano e contempla os aspectos socioambientais necessários aos processos de formação de equilíbrios produtores de esquemas que permitam visualizar outras facetas da participação e da percepção social. Mais fácil seria se a própria educação pudesse se pautar por movimentos autogestionários que beneficiam o diálogo, a organização política, o gerenciamento de conflitos e as buscas de soluções, conforme proposto pelo movimento das escolas democráticas.

Singer (2010) define essas escolas como locais em que todos participam ativamente da vida escolar, tomando decisões concernentes à administração da própria escola e dos conteúdos a serem estudados, dando uma característica não compulsória e participativa nomeada de "república de crianças". Quão tranquilo seria o enfrentamento da economia de mercado e das adequações pela ecosol se seus participantes viessem de experiências educacionais dialógicas. Mais que isso, pelo que as pesquisas em desenvolvimento moral demonstram, se essas pessoas chegassem à vida adulta vivendo em espaços facilitadores da constituição da personalidade ética e com grande probabilidade de então exercer de fato a cidadania e a política.

A emancipação política e social, bem como a democracia, podem ser favorecidas por empreendimentos econômicos solidários por permitir que fatores particulares se tornem lutas coletivas, constituindo-se em lugares comunitários. Laville (2016) aponta que "nesses processos de constituição de espaços públicos, podem aparecer muitas ações cidadãs que não são apenas fruto de uma ação racional: recursos emocionais ou afetivos são igualmente mobilizados para tornar públicas questões que antes eram da ordem do privado" (p. 371).

Dessa forma, a união de espaços coletivos cooperativos, ações individuais e presenças cognitivas e afetivas compõe os aspectos necessários ao crescimento humano e à sustentação de relações sociais democráticas, aquele arrolado pelo bem comum e 
estas definidas pelo interesse bem compreendido. Nesse caso, o desenvolvimento da moralidade humana constitui-se em um dos aspectos que podem favorecer a democracia e a ecosol, as quais conseguem, por conta de seus projetos educativos, auxiliar na constituição da noção de justiça, facilitar a passagem da heteronomia para a autonomia moral, a inclusão das virtudes como centrais na vida e, consequentemente, a formação da personalidade ética. Ou seja, as apurações das condições individuais humanas e da sociedade estão imbricadas na inter-relação entre aspectos individuais do desenvolvimento e condições socioambientais que facilitem os processos. Em outros termos, tanto a ecosol pode facilitar a emergência de uma personalidade ética como a personalidade ética pode auxiliar na construção de espaços democráticos em que a ação coletiva sobrepuje a individual.

\section{Considerações finais}

Apresentamos diversos elementos comuns aos dois objetos estudados: cooperação, reciprocidade, princípios democráticos, justiça, bem comum, que talvez sejam definidores tanto da ecosol quanto da psicologia moral. Vimos que a constituição ética depende da autonomia moral, da expansão de si e da incorporação no centro da personalidade de virtudes; e mais: que ao definir o valor de nossas próprias características, investimos emocionalmente a ponto de constituir uma escala de valores, responsável por conduzir nossas ações e por se manter firme diante das exigências sociais e das tentações cotidianas. É a escala de valores que faz com que optemos por estudar em vez de ir a uma festa, por exemplo.

A personalidade ética é dependente de diversos elementos sociais que ao longo da vida podem ou não favorecer o seu aparecimento. $O$ ideal é termos processos institucionais, sejam eles escolares ou não, participando do desenvolvimento da moralidade. No entanto, pelo caráter coercitivo das relações sociais e das escolas brasileiras, as crianças e adolescentes vão para a vida adulta e em sociedade sem terem adquirido tais elementos. Nessa perspectiva, aqueles que em maioria trabalham em empresas capitalistas nem perceberam que competição e/ou exploração foram naturalizadas, mas aqueles que rumam para a ecosol sentirão de imediato as dificuldades para se posicionar diante das novas ideias e tomadas de decisão. A psicologia moral nesse sentido pode auxiliar ao participar do debate e fornecer conhecimentos para a elaboração de formações e intervenções em incubadoras ou em programas nacionais de fomento à ecosol.

Cabe ressaltar que essa área de conhecimento, tal como as outras, tem suas limitações, que devem ser enumeradas: a primeira refere-se ao fato de que os estudos piagetianos são baseados no juízo, e não na ação moral. Dito de outra forma, estuda-se a consciência moral, e não o comportamento em si, entretanto acredita-se que quanto mais elevada a consciência moral, maiores as chances de adquirir 
comportamentos morais; outro ponto de destaque é que são quase inexistentes pesquisas acerca da moralidade fora de ambientes escolares ou com adultos, colocando nosso debate aqui no campo das hipóteses e ressaltando a importância de aprofundamento e de pesquisas empíricas sobre o tema; o terceiro ponto é que, apesar de existirem inúmeras pesquisas demonstrando a eficácia de propostas educacionais para o desenvolvimento, nenhuma delas foi realizada com adultos e muito menos em empreendimentos econômicos solidários; por fim, é quase inexistente o uso dessa área do conhecimento para pensar ou processos organizacionais, ou trabalho ou trabalhadores, ficando o debate restrito à psicologia organizacional e do trabalho.

É justamente por essas limitações que o debate ora proposto se faz necessário ao ampliar o foco da psicologia moral para outros ambientes, além da família e da escola, e adentrar em áreas relativamente estabelecidas pela psicologia do trabalho e da administração. Isso demonstra que os estudos acerca da personalidade ética contribuem de forma significativa para pensarmos novos fatores intervenientes da ecosol e novas esferas sociais capazes de favorecer o desenvolvimento humano.

Apresentamos também que a ecosol como escopo teórico é rizomática, produzindo diversos entendimentos que ora flertam com o mercado capitalista, ora se Ihe opõem ou tentam suplantá-lo; bem como visões que enquadram a ecosol como movimento social dentro da lógica atual de reivindicações de direitos e reconhecimentos identitários, ou como um movimento capaz de alterar subjetividades aumentando a consciência coletiva e as sociabilidades estabelecidas. Nesse sentido, defendemos que a ecosol carece de uma visão psicológica que compreenda os fatores relacionados ao desenvolvimento e aos modos de ser e de fazer humanos na sociedade. Esse olhar pode ser oferecido pela psicologia moral, precisamente por considerar fatores subjetivos de constituição de si que compõem com elementos tão caros à ecosol. Saber trabalhar coletivamente, ter uma escala de valores composta por fatores morais e posicionar o bem coletivo à frente do individual devem ser pensados do ponto de vista da construção da personalidade na interface dos relacionamentos com o meio.

Assim como Benini e Benini (2015) e Laville (2016), consideramos que a ecosol tem as condições necessárias para produzir alterações nas subjetividades humanas individuais e coletivas, modificando as formas de os sujeitos se portarem socialmente e brincarem/lutarem com o jogo do sistema econômico vigente. Para além de constituir uma consciência coletiva, a ecosol pode atuar na transformação das estruturas psicológicas individuais, estabelecendo sociabilidades que alteram o social. Somente dentro dessa perspectiva é que acreditamos na possível condição de suplantação de modelos de exploração do humano. 


\section{Referências}

Albuquerque, P, P. (2003). Autogestão. In A. D. Cattani (Org.), A outra Economia (pp. 20-25). Porto Alegre, RS: Veraz.

Aristóteles. (2009). Ética a Nicômaco. São Paulo, SP: Edipro.

Azambuja, L. R. (2009). Os valores da economia solidária. Sociologias, 11(21), 282-317. doi:10.1590/S1517-45222009000100012

Benini, E. A., \& Benini, E. G. (2010). As contradições do processo de autogestão no capitalismo: Funcionalidade, resistência e emancipação pela economia solidária. Organizações \& Sociedade, 17(5), 605-619. doi:10.1590/S198492302010000400002

Benini, E. A., \& Benini, E. G. (2015). A construção do trabalho associado sob a hegemonia estatal: Organização, solidariedade e sociabilidade. Organizações \& Sociedade, 22(74), 325-344. doi:10.1590/1984-9230742

Borges, T. P. (2014). Os atores da economia solidária: Estudos sobre personalidade ética (Tese de doutorado). Universidade do Estado de São Paulo, São Paulo, SP.

Boronat, A. (2010). Las cooperativas de trabajo en Castilla y León: Comprometidas con el empleo y con el desarrollo local. In J. E. F. Arufe, J. M. G. García, \& A. R. Ortega (Coords.), Estudios de economía social (pp. 353-394). Valladolid: Universidad de Valladolid.

Cançado, A. C., Tenório, F. G., \& Pereira, J. R. (2011). Gestão social: Reflexões teóricas e conceituais. Cadernos EBAPE.BR, 9(3), 681-703. doi:10.1590/ S1679-39512011000300002

Castel, R. (2015). As metamorfoses da questão social: Uma crônica do salário. Petrópolis, RJ: Vozes.

Comte-Sponville, A. (1995). Pequeno tratado das grandes virtudes. São Paulo, SP: Martins Fontes.

Demo, P. (2005). Éticas multiculturais: Sobre convivência humana possível. Petrópolis, RJ: Vozes.

Demo, P. (2006). Pobreza política: A pobreza mais intensa da pobreza brasileira. Campinas, SP: Autores Associados.

Freitas, L. (2003). A moral na obra de Jean Piaget: Um projeto inacabado. São Paulo, SP: Cortez.

Gilligan, C. (1982). Uma voz diferente. Rio de Janeiro, RJ: Rosa dos Tempos. 
Instituto de Pesquisa Econômica Aplicada (2018). O campo da pesquisa da economia solidária no Brasil: Abordagens metodológicas e dimensões analíticas. Rio de Janeiro, RJ: Autor.

Kohlberg, L., Boyd, D. R., \& Levine, C. (2002). O retorno do estágio 6: Seu princípio e ponto de vista moral. In A. Biaggio, Lawrence Kohlberg: Ética e educação moral (pp. 100-131). São Paulo, SP: Moderna. (Trabalho original publicado em 1990).

La Taille, Y. (1994). Prefácio. J. Piaget, O juízo moral na criança (pp. 7-22). São Paulo, SP: Summus.

La Taille, Y. (2000). Para um estudo psicológico das virtudes morais. Educação e Pesquisa, 26(2), 109-121. doi:10.1590/S1517-97022000000200008

La Taille, Y. (2006). Moral e ética: Dimensões intelectuais e afetivas. Porto Alegre, RS: Artes Médicas.

La Taille, Y. (2009). Formação ética: Do tédio ao respeito de si. Porto Alegre, RS: Artmed.

La Taille, Y. (2010). Moral e ética: Uma leitura psicológica [Edição especial]. Psicologia: teoria e pesquisa, 26, 105-114. doi:10.1590/S0102-37722010000500009

La Taille, Y., \& Cortella, M. S. (2005). Nos labirintos da moral. Campinas, SP: Papirus.

Laville, J. L. (2016). Repensando o espaço público e a economia: Contribuição da economia solidária à teoria da democracia. Organizações \& Sociedade, 23(78), 369-377. doi:10.1590/1984-92307812

Mance, E. A. (1999). A revolução das redes: A colaboração solidária como uma alternativa pós-capitalista à globalização atual. Petrópolis, RJ: Vozes.

Mothé, D. (2009). Autogestão. In A. D. Cattani, J. L. Laville, L. I. Gaiger, \& P. Hespanha (Coords.), Dicionário internacional da outra economia (pp. 26-30). Coimbra: Almedina.

Oliveira, E. M. (2017). Economia solidária no Brasil: Elementos de uma dialética e dialógica do fracasso - causas possíveis, correções necessárias, desafios inevitáveis. Cronos, 18(2), 46-71. Recuperado de http://bit.ly/3aDtcFI

Pedro-Silva, N., \& Ferreira-Costa, R. Q. (2017). Jean Piaget e relações interpessoais no trabalho. Revista Laborativa, 6(2), 39-58. Recuperado de http://bit.ly/2xmpTV2

Piaget, J. (1994). O juízo moral na criança. São Paulo, SP: Summus. (Trabalho original publicado em 1932).

Piaget,J. (1994). Lasrelacionesentrelainteligenciaylaafectividadeneldesarrollodel niño. In G. Dalahanty \& J. Perrés (Orgs.), Piaget y el psicoanálisis (pp. 181-289). 
Ciudad de México, México: Ed. Universidad Autónoma Metropolitana. (Trabalho original publicado em 1953).

Picolotto, E. L. (2008). Novos movimentos sociais e econômicos: Economia solidária e comércio justo. Outra Economia, 2(3), 74-92. Recuperado de http://bit.ly/39HeFZt

Pinheiro, D. C. (2013). Economia solidária: Uma revisão teórica a partir dos seus "múltiplos" conceitos. Revista Nau Social, 3(5), 85-105. Recuperado de http://bit.ly/2TDFUyu

Puig, J. M. (1998). A construção da personalidade moral. São Paulo, SP: Ática.

Ramozzi-Chiarottino, Z. (1988). Psicologia e epistemologia genética de Jean Piaget. São Paulo, SP: EPU.

Ramozzi-Chiarottino, Z. (2003). Prefácio. In L. Freitas, A moral na obra de Jean Piaget: Um projeto inacabado (pp. 11-12). São Paulo, SP: Cortez.

Secretaria Nacional de Economia Solidária. (2004). Termo de referência para o mapeamento da economia solidária e sistema nacional de informações em economia solidária. Brasília, DF: Autor.

Singer, H. (2010). República de crianças: Sobre experiências escolares de resistência. Campinas, SP: Mercado das Letras.

Singer, P. (2002). Introdução à economia solidária. São Paulo, SP: Fundação Perseu Abramo.

Santos, A. M. (2014). Os dilemas da organização popular no movimento da economia solidária no Brasil. Otra Economía, 8(15), 196-209. Recuperado de https://bit.ly/34lggCx

Sistema Nacional de Informações sobre Economia Solidária. (2018, 30 de outubro). Recuperado de http://sies.ecosol.org.br/sies

Tauile, J. R. (2002). Do socialismo de mercado à Economia Solidária. Revista de Economia Contemporânea, 10 semestre de 2002.

Taylor, C. (2011a). A ética da autenticidade. São Paulo, SP: É Realizações.

Taylor, C. (2011b). As fontes do self: A construção da identidade moderna. São Paulo, SP: Loyola.

Tiriba, L. (2008). Cultura do trabalho, autogestão e formação de trabalhadores associados na produção: Questões de pesquisa. Perspectiva, 26(2), 69-94.

Tocqueville, A. (2000). A democracia na América: Sentimentos e opiniões. São Paulo, SP: Martins Fontes. 
Tognetta, L. R. P. (2003). A construção da solidariedade e a educação do sentimento na escola. Campinas, SP: Mercado de Letras.

Tognetta, L. R. P. (2009). Perspectiva ética e generosidade. Campinas, SP: Mercado de Letras.

Vinha, T. P. (2009). O educador e a moralidade infantil: Uma visão construtivista. Campinas, SP: Mercado de Letras.

\section{Agradecimentos}

À Fundação Universidade Federal do Tocantins pela licença concedida durante o período de trabalho de pesquisa.

\section{Sobre os Autores}

\section{Thelma Pontes Borges}

Doutora em psicologia escolar e desenvolvimento humano pela Universidade de São Paulo. Professora do Programa de Mestrado em Demandas Populares e Dinâmicas Regionais da Universidade Federal do Tocantins. E-mail: thelmapontes@uft.edu.br. ORCID: 0000-0001-6073-8937

\section{Maria Thereza Costa Coelho de Souza}

Livre-docente em psicologia escolar e do desenvolvimento humano pela Universidade de São Paulo (USP). Professora titular do Departamento de Psicologia da Aprendizagem, do Desenvolvimento e da Personalidade do Instituto de Psicologia da USP. E-mail: mtdesouza@usp.br. ORCID: 0000-0002-9802-0864 